\title{
Douleur et personne âgée
}

\section{Pain and elderly}

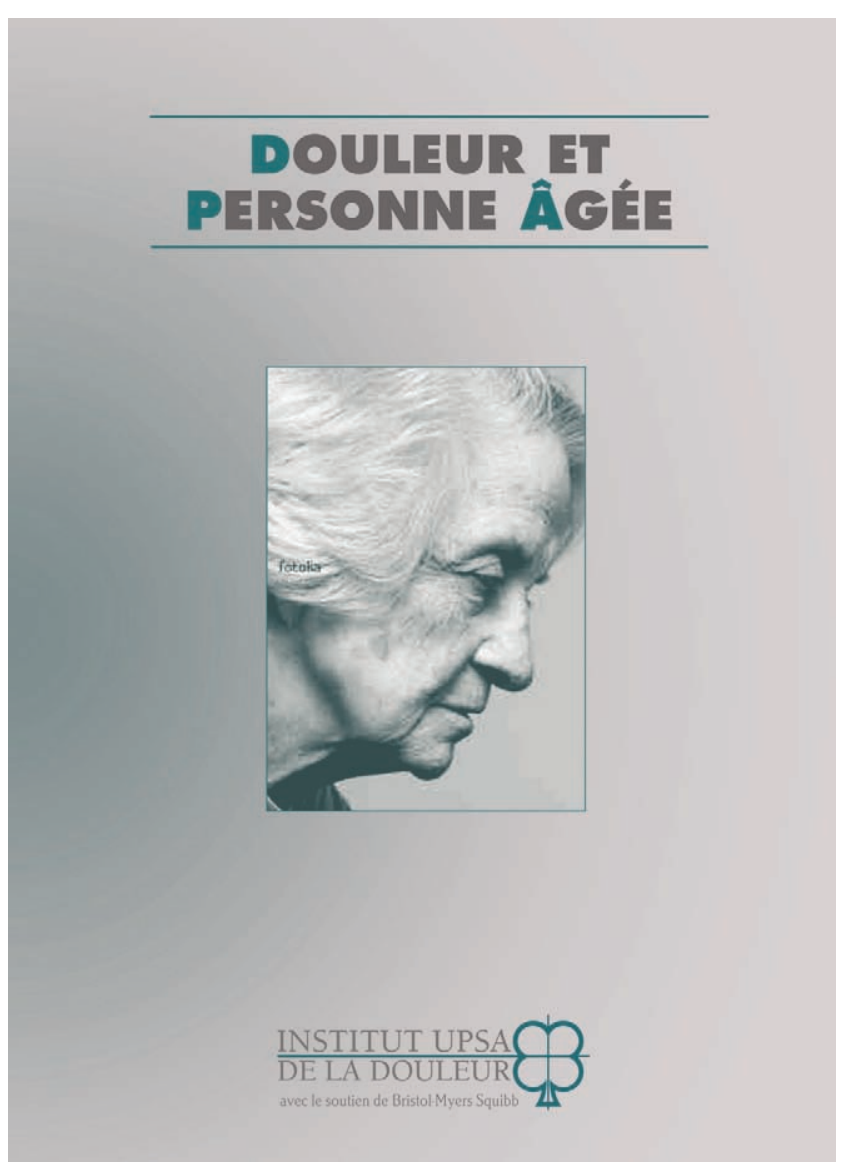

Parce qu'être âgé et souffrir est souvent considéré à tort comme normal, la problématique de la douleur chez la personne âgée se doit d'être éclairée, c'est tout l'enjeu du dernier ouvrage édité par l'Institut UPSA de la Douleur.

Cet ouvrage « prend la vieillesse au sérieux, quand notre société, trop souvent, préfère l'oublier ou la minorer. Il prend la souffrance au sérieux, quand il fut longtemps de bon ton, dans nos hôpitaux, de n'y voir qu'un symptôme incommode ou encombrant. Il donne les moyens de la mesurer, de l'évaluer, de la comprendre, de l'affronter, de la soulager. Il met nos soignants devant leurs responsabilités ; et nous tous, en tant que citoyens, devant les nôtres. ") tels sont les propos d'André Comte-Sponville qui a rédigé la préface.

Coordonné par le Docteur Gisèle Pickering (Centre de Pharmacologie Clinique, INSERM U766 et CIC 501, Faculté de Médecine et $\mathrm{CHU}$ de Clermont-Ferrand), ce nouvel ouvrage a bénéficié de l'intervention d'auteurs de renom non seulement français mais, pour la première fois, internationaux.

« Douleur et Personne Agée » est téléchargeable sur www.institut-upsa-douleur.org 